\title{
Research on Optimization Design of Primary School Students' Homework in Xi'an
}

\author{
Ying Cao, Shuang Wang, Xinlei Mao \\ Xi'an University, 710065
}

Keywords: Xi'an; Primary School Students; Homework; Optimization

\begin{abstract}
Burden reduction of primary school students has been a hot social issue. Homework, as the main learning task of pupils after class, plays an important role in consolidating the learned knowledge. But at present, there are still some problems in homework design and arrangement of primary school students. These problems are caused by both social aspects and teachers' understanding and school management. How to optimize the homework design of the pupils is a realistic problem to be solved urgently in the new era. This paper makes a brief analysis of the current situation of homework in primary schools in Xi'an and expounds how to develop and optimize the design.
\end{abstract}

Homework plays an important role in pupils' study.Homework is the basic link in primary school students' study,and is the link and bridge between curriculum and teaching.Homework plays an irreplaceable role in pupils' consolidation of classroom knowledge,skill formation and ability development.However,as far as the overall design and arrangement of pupils' homework is concerned,many teachers do their homework at will,and have not fully taken into account the scientific and rational nature of the homework assigned to pupils so that homework has evolved into workbooks outside the classroom.In some schools,homework is so uniform in content and form that it doesn't excite students interest in learning.In addition,some school homework not according to the actual study of students,so as to teach students in accordance with their aptitude,but a large number of exercises as the basis of homework,students have brought a heavy burden.

Now,in the background of advocating liberal education,in reducing the schoolwork burden of primary school students,we must face the problem of homework with a very rigorous attitude. This is not only an educational problem,but also a social problem,and its solution needs the attention and joint efforts of the whole society.

\section{The value of homework in primary school students.}

At present,some educators hold a more radical attitude in reducing the burden on students.In their view,primary school students are at a specific stage of growth.Students at this stage can achieve their educational goals basically by learning in the classroom,without the need for extra homework.Some scholars believe that homework is a necessary means for pupils to digest and consolidate knowledge and should be strengthened.From a single point of view,these two ideas have no problems,but if placed in the general environment of education and teaching,placed in China's current education system,the two ideas have this kind of problem.Is Homework valuable or 
not?Foreign countries are more casual in dealing with homework. They have less homework assignments for students, and secondly, they pay more attention to cultivating students' innovative thinking and hands-on ability.Of course,this has a very close relationship with the foreign education and teaching system.In the West,students are not required to study too much theoretical knowledge at the primary school level,and they believe that the primary school level students are mainly to play-based.Many Chinese students transfer to foreign countries,often do not adapt to the loose educational and teaching environment.Compared with foreign countries,China's educational and teaching system is quite different.Primary school is considered to be an important period for learning theoretical knowledge.After class,it is difficult for students to keep up with their homework if they do not do certain homework exercises.At the same time, homework is usually done by students independently.This process can effectively improve students' independent thinking ability,cultivate students' good study habits,and help students build up self-confidence and sense of achievement.Through homework,parents can also timely detection of students' learning status,understand students' learning progress.Homework can also enhance communication and communication between students and parents,and increase parent-child relationship.

Therefore,in China's current education and teaching system,homework has its inevitability.We should attach importance to and study the problem of how homework should be presented to students and how homework can be used to improve students' comprehensive quality and ability no longer make homework a burden for students.

\section{Homework status of primary school students in Xi'an}

The author investigates and tracks the current situation of homework among primary school students in Xi'an.Generally speaking,the current situation of homework among primary school students in Xi'an has the following problems:

\subsection{The work is not targeted.}

The Xi'an Municipal Government and the education bureau attach great importance to the homework problem of primary school students.They have also introduced some restrictive measures,such as setting a maximum time limit for students' homework,the content of homework, etc.But in fact,each school in order to ensure the rate of students and the quality of teaching,are disguised expansion of the students homework content.Some teachers regard homework as an extension of classroom teaching,and set some classroom teaching contents as homework.Some teachers decompose the preview content into work assignments to students in advance and so on.These homework is only staged for the teaching results,the lack of long-term planning and scientific design,there is no strong targeted,and some even for the homework set.Such homework is not only not conducive to the growth of students,students will even make exhausted and no efficiency.

\subsection{The format is inflexible}

Pupils in Xi'an also tend to have more rigid forms of homework,mainly theory-based intensive learning,with less practical and applied learning,and less written and oral homework.Homework is mostly assigned by schools and teachers,less self-designed by students,more mechanical copying and calculation,less close to students' learning interests,more one-size-fits-all homework,less teaching assignments. These rigid homework form is not conducive to the implementation of students' personality, ignoring the individual differences of students. 


\subsection{The work content lacks timeliness}

Many teachers don't fully understand the value of homework,and the homework they assign is basically a repetition of the day's work.For Students,this kind of work is not only lack of interest,but also lack of challenge, which is not conducive to broaden students' vision,and is not conducive to the development of students' interest in learning.Due to the limitations of our education system and curriculum time,our primary school homework generally follows the principle of consistency.That is to say,all students,regardless of your progress,have different levels of ability and need to complete the same homework. This kind of undifferentiated homework system is not only a burden for students with strong learning ability,but also a burden for students with poor learning ability.

\subsection{The evaluation system is backward}

In a way,our homework evaluation system is very backward.To what extent does it lag behind?It almost does not have any guiding value and guiding role.Many teachers in the assessment of students homework,just a simple check under the wrong, there is no error in-depth analysis and research.Errors in homework are usually corrected by the students themselves,and they are not systematically analyzed to form well-directed guidance.Some teachers will review homework class cadres or class representatives to complete,their only occasional round of inspection.

\section{Homework problems for primary school students in Xi'an}

Too much or unreasonable layout and designs primary school students homework has brought to schools and families this and that kind of problem.Some problems have been very prominent,to the point that can not be solved.

\subsection{Students had less spare time}

Primary School stage is an important stage of personal growth and development.In advocating the liberal education today,primary school students learning habits good or bad,the level of learning ability on its subsequent development will have a tremendous impact.At present,too much homework in Xi'an's primary schools is still a serious problem. The result is that students are being squeezed out of their spare time.We do not deny the importance of reading, but in today's society,a person's all-round development than in the death of reading,reading death is more important.Homework takes up too much of a student's precious free time,and many have no time for the joys of childhood beyond the overwhelming amount of homework they do.

\subsection{Pubic myopic proportion is high.}

At present,due to the heavy pressure of social competition,parents and schools are very much looking to the rate of further education for their children's future development,and are doing everything they can to improve their children's academic performance.Multitasking seems to be the easiest and most straightforward way for kids to improve their grades.In such an environment,the proportion of primary school students suffering from Myopia is increasing year by year.The author conducted a special survey on this issue in a primary school.Among them,the rate of Myopia among students in a first grade class was $5 \%$, and by the second grade,the rate had risen to $10 \%$.In the fourth grade,the rate was an astounding 50 percent.As children's glasses get thicker and thicker,the price they pay for improving their academic performance can be painful. 


\section{Strategies for optimal homework design for primary school students in Xi'an}

\subsection{Break the shackles of the traditional educational and teaching concepts}

First of all,we should break the shackles of the traditional teaching idea.Teachers should establish the correct concept of homework,realize the real purpose of homework,and adjust the direction of education and teaching to improve students' comprehensive ability and quality,adjust to improve students' ability to solve practical problems,and adjust to cultivate students' innovative thinking.Homework should not be limited to the written form,but can be a practical endeavor.We should also pay attention to the differences reflected in homework,earnestly implement people-oriented,respect for individual differences, and do our best to teach students in accordance with their aptitude.

\subsection{Scientific Planning Workload.}

How much homework can meet the needs of education and teaching,but also to consolidate knowledge.This may seem like a hard problem to quantify,but it's one we have to deal with.How to plan the amount of homework scientifically?In view of this problem,many scholars have put forward their own point of view,no matter in theory or in practice,have carried out fruitful exploration and bold attempt, generally speaking,and it worked.The planning of primary school students' work load should fully consider the teaching progress,students' work and rest time,etc.At the same time,the form of homework for primary school students is also one of the important factors to be considered.We should no longer say that primary school students' homework is limited to a specific form,but should be flexible and varied, students like to see the way.

\subsection{Have a sense of hierarchy in your homework}

In the design of homework,we should take into account the learning ability and learning progress of different students. We should abandon the traditional model of one-size-fits-all homework, with a three-dimensional sense of the level of design.For example,some homework is required to be completed,some homework can be selectively completed,some homework is in a way of thinking,etc. This approach not only caters to the actual needs of students at different levels,but also provides each child with flexible learning space.

\subsection{Keep your home-school contacts close}

In the primary school learning stage,the school and the family close cooperation regarding student's study growth is playing the very tremendous function.Pupils are still mentally immature,and many of their views and understanding require the combined efforts of school and Family to develop healthily.the same is true for homework.Many parents also worry when their children's homework is too much.They worry that their children can not bear such pressure.But when their children's homework is too little,they worry that their children will be lazy and do nothing.Therefore,schools and parents should strengthen contact,keep abreast of students' learning trends,to help students complete the primary school learning process.

\section{Conclusion}

To sum up,the learning of primary school students affects the nerves of every school and family.How to make primary school students improve their learning efficiency.It is the common 
wish of teachers and parents to have a bright future.As long as teachers and parents work together,try to use their brains in their students' study and homework,discard the idea that more is better than more,and pay attention to science and effectiveness,homework will no longer be a headache for students It's something that students enjoy doing.

\section{Acknowledgements}

The results of the 2018 national innovation project "practical research on optimization design of homework for primary school students in xi 'an", project number: 201811080017.

\section{References:}

[1] Wang Yanxia.Strategies for optimizing the design of homework for primary school mathematics. Youth and society [J], $2012(02)$

[2] Song Lihua,Li Rumi.The Path of Homework in Primary and Middle Schools from Alienation to Rational Regression[J].Teaching Theory and Practice,2011(11)

[3] Ren Baogui,Chen Xiaoduan.American Homework Policy and Its Enlightenment[J]. Educational Science,2010(26)

[4] Li Surin.Reflections on the Extracurricular Assignment of Pupils[J].Teaching and Management,2001(22)

[5] Liu Yanzun.Reflections on Student Assignment [J].Reading and Appreciation (teaching and research edition),2005

(6)

[6]Yu Yanting.Analysis of the Path of Psychological Suggestion in Middle School Students' Moral Education [J].New West (Theoretical Edition), 2015(16) 